\title{
Mega-events as a Response to Poverty Reduction: The 2010 FIFA World Cup and its Urban Development Implications
}

\author{
Udesh Pillay • Orli Bass
}

Published online: 4 June 2008

(C) The Author(s) 2008

\begin{abstract}
This paper reflects on the trajectory that urban development associated with the 2010 Fédération Internationale de Football Association (FIFA) World Cup has taken in South Africa. The argument suggests that a unique moment has been lost regarding the ability of the World Cup to serve as a catalyst for urban development. This notion is supported by a digest of the international literature which takes a cautious stance in its assessment of the benefits of mega-events. Hence, this paper posits that it is unlikely that poverty alleviation, as a result of fasttracking South Africa's urban development impetus, will constitute a significant outcome of the World Cup. Rather, development benefits in cities are likely to be fairly circumscribed. Legacy, the paper argues, should therefore advance beyond an exclusively pro-poor language. In this regard, vigorous public debate is required to arrive at a national consensus of what kind of legacy the 2010 FIFA World Cup is realistically able to achieve.
\end{abstract}

Keywords Mega-events · Developing world · Poverty · Urban development · Legacy

\section{Introduction}

The decision in May 2004 by soccer world body Fédération Internationale de Football Association (FIFA) to award South Africa the right to host the 2010 World Cup has shifted the spotlight onto South African cities, and their ability and readiness to cope. This occasioned much subsequent analysis of infrastructure and

U. Pillay

Human Sciences Research Council (HSRC), 134 Pretorius Street, Pretoria 0002, South Africa

O. Bass $(\bowtie)$

Human Sciences Research Council (HSRC), 750 Francois Road, Intuthuko Junction, Cato Manor, Durban 4001, South Africa

e-mail: obass@hsrc.ac.za 
service delivery readiness. While informed opinion has increasingly suggested that South African cities will, indeed, be in a position to successfully host the tournament in 2010, widespread consensus also suggests that much still needs to be done between now and then. South Africa is the first African nation to host such a megasporting event, prompting President Thabo Mbeki to pronounce that this is not a South African event but an African one. Much is expected from a host nation, and global attention has focused on the opportunities and threats that come with such an ambitious undertaking, especially for a transitional democracy recovering from years of spatial, racial and political fragmentation.

The developmental impacts of mega-events in the periphery are frequently touted, although there is little guarantee that the actual effects will contribute to poverty reduction specifically. In situating mega-events as a response to poverty alleviation, as many scholars, political commentators and observers have been inclined to do, careful consideration is required in order not to over-inflate their legacies as a panacea to a country's developmental challenges. In outlining this notion, the paper contextualises this issue within the broader literature concerning mega-events in the developing world. Paying close attention to the relationship between growth and equity, the overall aim of the paper is to provide insight into the 2010 FIFA World Cup in relation to development prospects for South Africa, and in particular, its major urban areas.

In this regard, the paper seeks to overcome some of the euphoria associated with the benefits mega-events like the 2010 FIFA World Cup are presumed to generate, and pays particular attention to assessing the actual developmental impacts. These can be quite circumscribed and, as evident from the international literature, there are at times long-term costs associated with the hosting of mega-events that have had serious consequences for the national economies of host countries. For example, while there may be low-and-intermediate skilled job creation opportunities in the construction and built environment sectors ahead of 2010 , these are likely to be mostly short-term and/ or temporary employment opportunities involving finite numbers. In effect this does little to help appreciably reduce unemployment rates, and has only a marginal spin-off impact in downstream communities living in conditions of poverty and squalor hoping to benefit from remittances. On the other hand-as will be articulated in further detail later - the legacy that 2010 is likely to leave behind should not be articulated solely in pro-poor rhetoric. We will advance this latter argument in due course.

\section{Urban Development}

Urban development and renewal has been identified by government as a key national imperative. As such, assessing the development implications of hosting the World Cup in 2010, especially at a time in which government's urban renewal strategy is (eventually) gaining momentum, becomes critical. With high urbanisation rates projected, with the six 'big' metropolitan economies currently contributing the majority of the national gross domestic product (GDP), and with service, infrastructure and income disparities widening in urban areas, initiatives aimed at stimulating economic growth and job creation need to be carefully nurtured and sustained (Pillay et al. 2006; Pillay 2004). Two years ago, it appeared that the hosting of the FIFA World Cup in 2010 had the potential to do precisely this.

烈 Springer 
At that time, it seemed that the event presented South Africa with a unique opportunity to fast-track the development impetus in cities and larger towns. If a programme of action was well-conceptualised and formulated, the spin-offs for cities could be immeasurable. Developments since then, at both national and local level, have not been insignificant.

The national government has outlined its blueprint for how the roll-out of this massive public works undertaking should commence, and the host cities have begun planning in earnest. A lack of communication, both vertically and horizontally, has been a problem, but much attention has been given to this recently. The signs are therefore encouraging, and the debate over policy and process has given way to a not unreasonable amount of consensus, with the actual business of construction and development now proceeding apace. Decisions around stadium upgrading and infrastructure development seem, to an extent, to have been subject to democratically based decision-making processes, with growth, equity and sustainability principles seen as mutually reinforcing, if not finding necessary expression in the plans themselves. As the literature reminds, excluding such principles often has very harmful consequences for cities and their long-term future.

Having said this, mega-events are often used as 'spectacles' that can best be understood as either instruments of hegemonic power, or displays of urban 'boosterism' by economic elites wed to a particularly narrow-minded pro-growth vision of the city. As such, these events are often seen as no more than public relations ventures far removed from the realities of urban problems and challenges. 'Welfarist' and equity-based considerations tend to be conspicuously absent.

South African planners did, however, even if just at the bid stage of the 2010 event, draw on the experiences of countries in which significant opposition was generated from marginalised and powerless communities who saw little material benefit accruing from such events. Drawing also from a wide body of literature attesting to the ability of mega-sporting events to truly nurture a holistic development path, and taking important lessons from the Cape Town Olympic bid experience into account, planners considered two elements to be vital.

First, the tournament needed to be conceived as providing a catalyst for improving the life conditions of the historically disadvantaged (this is meticulously spelt out in the bid blueprint); and, second, re-designing the apartheid city in order to create new functional linkages needed to become a central thrust, with a series of action plans then convincingly illustrating how this was likely to be achieved. An integrated public transport system came to mind here.

A very comprehensive and well-grounded bid plan thus emerged which, in essence, laid the foundation for a truly meaningful development agenda. However, it remained no more than a blueprint unless the essence and spirit that underpinned its key pillars were enforced in a programme of development that talked to the twin, and often competing, demands of what was required in terms of FIFA's technical specifications, and what was the broader development imperative of a host nation. At this stage, what was required among scholars and practitioners was the start of a robust debate that ensured that the work of the local organising committee (LOC), and all the other major players, started and was sustained on the basis in which the bid was conceived. There need not have been anything intrusive about such a public engagement with the work of the LOC and the cities, as it is well-documented that 
appropriate checks and balances are always a necessary pre-requisite to desirous outcomes. A well-functioning and confident LOC, and industrious and hardworking cities may have, indeed, welcomed such debate, despite their contractual obligations and responsibilities. Some of the questions that were key in informing such debate included the following:

1. What were the current capabilities of, and what was the state of readiness among, South African cities to host this event?

2. In the run-up to the event, could urban development and renewal-especially in the six major urban conurbations-be fast-tracked, and how?

3. Was it possible that growth and equity issues could become truly reinforcing concepts in a sustainable programme of urban development and renewal preceding the event?

4. How could a well-grounded programme of urban development (initiated well before the event) take root and be sustained well into the future, with multiple spin-offs for all city dwellers, in particular the poor and marginalised?

5. What were public perceptions of the impact hosting the event was likely to have on their livelihoods?

6. How could the potential of the event to place South African cities among a global hierarchy of competitive metropolitan economies be measured?

The list was not exhaustive, but the start of a process of constructive and responsible engagement at some level needed to have begun. Vigorous public debate would provide direct insight and a nuanced multi-dimensional understanding of the development consequences of hosting a mega-sporting event. The process of debate, dialogue and reflection on the one hand, and the then immediate business of construction and infrastructure upgrading on the other, were not mutually exclusive processes, and necessarily needed to inform each other. They were processes that needed to run in parallel, with both providing an important set of checks and balances, despite deliverables that were cast in stone and time-frames that simply had to be met. No doubt politics and constituency-based agendas would intersect with the above processes, but this too was a healthy development provided it did not impede progress.

If all of the above happened, the basis for pro-active planning to ensure maximum benefit for all South Africans, especially the poor and marginalised, was likely to take root. Unique opportunities to fast-track the urban development impetus in cities and larger towns were likely to ensue, with significant policy implications for how government needed to start thinking about city-wide renewal, development and regeneration strategies. It was even possible that South African cities would be able to recreate their personalities in this process, allowing them to compete in an increasingly homogenised world, and enhancing their image and aesthetic status on the global stage. South African cities could potentially become "must see, must visit, must invest" places, as Speake (2007:3) reminds in her influential essay on the creation of 'sensational' cities occasioned by the increasing need in a globalised world for cities to become 'distinct' and 'different'.

If this all came together as planned, South Africa was likely to see close to 200,000 visitors here in 2010, a boost to the economy to the tune of R60bn, and the creation of 150,000 new jobs. The boost to national pride, and the potential to nurture a true South African identity, while intangible benefits, was also likely to be significant. 


\section{Getting the Basics Right for 2010}

About a year later, while remaining enthusiastic about the event itself, it become clear that there was less reason to be optimistic about the associated development prospects. As mentioned before, the 2010 FIFA Soccer World Cup presented South Africa with a unique opportunity to 'fast-track' the urban development impetus. Yet, a close reading of the international literature on the hosting of mega-events, especially the significant portion of the literature that is cautionary in its tone and vocabulary about the benefits that may accrue to host nations, heightened awareness not to inflate development expectations. We will turn to the international literature shortly.

But there was an additional set of reasons that motivated this hypothesis, one more rooted in what was - or was not as the case may have been — happening on the ground among the host cities.

These became clear after having posed some cautionary reminders worthy of consideration by those involved in the process, especially those directly responsible for getting cities ready to host the event. They included, inter alia, local government practitioners, property developers, members of the construction industry, and others involved in the service sector.

First and foremost - and rather urgently - it was argued that a national development framework needed to be established that resonated with the key development objectives spelt out in the bid blueprint for which the LOC, in collaboration with the relevant line ministries in government, and the host cities, must take direct responsibility for overseeing and enforcing. While individual cities may well decide on the specific mechanics of implementing development plans, a core, non-negotiable set of development principles needed to be subscribed to that corresponded with those enshrined in the blueprint. This was absolutely critical and one way of ensuring that the necessary synergy was realised was by building this into the terms of reference for the many tenders that were about to be advertised, and for adjudicators to subsequently scrupulously evaluate submissions to make sure bidders complied with the development criteria.

Secondly, it was critically important that cities modulate and revise their preexisting set of development strategies to align with the development imperatives outlined in the bid book. This was potentially not too difficult since South Africa's larger cities had, in the recent past, developed a set of regeneration strategies that in most cases corresponded with the (city-based) development principles outlined in the bid. Indeed, bid drafters were at pains to highlight the pre-existing development trajectory of South African cities in the blueprint, arguing that hosting the World Cup would give renewed expression to a holistically grounded set of urban renewal and regeneration plans.

The problem though was that some cities aspired to do other things as well at that stage, like becoming world-class and globally competitive. Unfortunately (most) proponents of this idea subscribed to a formulaic, economic growth-centred model of urban development, in which benefits to the poor and marginalised will—eventuallyaccrue through 'trickle-down' effects. Embracing an almost exclusive neo-liberal, market-orientated approach, the idea here among advocates was to position cities like Johannesburg among a global hierarchy of competitive metropolitan areas. In light of this, what had to happen at the planning stage of the World Cup was that the underlying 
principles of this strategy needed to be re-negotiated, and a balance struck between the development imperatives that evolved as a result of the winning bid, and indeed the important need to make South African cities globally competitive, but with new ideologies and discourses of development at the core of this strategy.

Thirdly, as difficult as this was, South African cities needed to start co-operating, and the impulse to compete (albeit in a highly competitive environment then in which the host cities were still not chosen) needed to give way to an understanding that the potential benefits that accrue should be seen as national public goods. In other words, job creation, economic growth, improved service delivery and infrastructure development, and the forging of a collective identity, needed be realised and subsequently felt throughout the country, and not just in particular locales. While South Africa's cities are, indeed, engines of growth and the World Cup did present South Africa with unique opportunities to fast-track urban development, it also provided the country with a glorious chance to help reconstruct under-developed and peripheral areas. The aforementioned development framework needed to incorporate this. The South African Cities Network could also play a useful brokering role here among over-zealous cities.

Fourthly, one needed to tease out the nature of the relationship between FIFA and the LOC more carefully and with greater scrutiny. As representative of South Africa's interests (by overseeing the activities of the various agents that will deliver the World Cup), the LOC needed clarity from FIFA on what exactly its role was, what as a result it was mandated and entrusted to do, on whose behalf such a mandate was being undertaken, and how much autonomy it had in making decisions. As 'owner' of the event, and with profit generation very much in mind, FIFA could well dictate the nature of business arrangements, commercial partnerships and other economic transactions, which could have significant consequences for the kind of development agenda pursued. At the time, the LOC would have done well to sketch out the parameters of its role upfront with FIFA.

Finally, while public participation in the decision-making process was important, the impact of this was best realised if one understood what the public was thinking. Public perceptions vis-à-vis a range of World Cup issues needed to be constantly measured and analysed, and then to directly inform especially that part of the development agenda that spoke to the benefits that could potentially accrue to the poor and marginalised, in particular measures to mitigate poverty. Stadium construction and transport infrastructure upgrades needed to continue in earnest as time was running out, but the type and nature of development interventionespecially in disadvantaged communities - needed to evolve as perceptions were canvassed and public behaviour scrutinised.

These, then, were some of the more immediate cautionary pointers that were considered critical at the time in ensuring that the 2010 World Cup serve as a catalyst in 'fast-tracking' urban development in the country and, if conceptualised according to the parameters sketched above, benefit peri-urban and rural communities as well. None of these materialised to the extent that it was envisaged —or at least hoped for-and a unique moment was lost.

Reinforcing this more attenuated position with regard to the benefits that the event could deliver was a proper synthesis undertaken of the international literature, which was then contextualised. It is to this that the discussion now turns. 


\section{Development Impacts of Mega-events: Reflections from the International Literature}

The international literature reveals a growing scepticism over the extent to which hosting mega-events potentially results in economic growth or significant developmental impacts (Humphreys and Prokopowicz 2007; Whitson and Horne 2006; Owen 2005; Black and van der Westhuizen 2004; Baade and Matheson 2004; Horne and Manzenreiter 2004, 2006; Matheson and Baade 2004; Whitson 2004; Burbank et al. 2002; Emery 2001; Jones 2001; Higham 1999). A host of scholars conclude that while there are some positive economic and legacy impacts (Lee and Taylor 2005; Ritchie 2000), the urban economic impact is variable, intangible and ambiguous at best (Andranovich et al. 2001; Gratton et al. 2000, 2001, 2006). The purported legacy of mega-events (including social and economic legacies) has a lot to do with the 'element of the attraction' occasioned by the event, and to an extent has been achieved in some cases (Ritchie 2000). Yet, it also forms "part of the 'known unknowns' of the sports mega-events" (Horne and Manzenreiter 2006:9). Part of the reason for this ephemeral quality is that post-event analyses seldom occur as organisers disband and governments focus their attention on other activities (Horne and Manzenreiter 2006; Hiller 1998) ${ }^{1}$. Nevertheless, the gap between actual and predicted impacts remains a key concern of academics and the source of a burgeoning literature (Horne and Manzenreiter 2004, 2006; Whitson and Horne 2006; Cornelissen 2004a).

There are three categories of scholarly consensus concerning the exaggeration of benefits linked to mega-events. The first suggests that "the increase in direct spending attributable to the games may be a 'gross' as opposed to a 'net' measure" (Matheson and Baade 2004:1090). This figure fails to account for the consequences of mega-event spending resulting in the displacement of regular spending. Secondly, mega-events may crowd out regular business travellers in a particular region. In this regard, regular business travellers may avoid host cities for the duration of the event. Thirdly, the notion of the multiplier effect (which suggests that further spending is stimulated by initial, direct spending on mega-events) is criticised in one sense in that the multiplier for a mega-event "will be lower than the multiplier for spending on many other local goods and services" (Matheson and Baade 2004:1091).

Hence, in the context of the developed world, the impacts of mega-events are not uniformly positive. The Montreal Olympics had highly problematic long-term economic outcomes for the city. An analysis of the more recent 1994 World Cup in the United States of America revealed that opposed to the expected \$4 billion gain, host cities experienced losses ranging between \$5.5-\$9.3 billion (Baade and Matheson 2004; Matheson and Baade 2004). Non-host cities can also experience reductions in their revenue which may be long-lasting. Long-term gains in employment in Lillehammer, were counterbalanced by drops in non-host cites after the 1994 Olympics in Norway. Indeed, mega-events are transient events and longterm economic impacts in Lillehammer were minimal (Tilley 2006; Spilling 1998).

\footnotetext{
${ }^{1}$ For an exception to this trend, see Metropolis (2002).
} 
Moreover, while the Olympics in Barcelona is widely regarded as having been particularly successful, associated rises in the costs of services, transportation and food should serve as a warning signal, particularly to the developing world (Tilley 2006). Furthermore, job creation in Barcelona centred around low paid, temporary employment as opposed to any meaningful long-term job creation (Horne and Manzenreiter 2006).

In addition to these experiences, as Matheson and Baade (2004) suggest, displacement of public funds is a key area of complaint. Public spending on projects and maintenance often means that budget cuts are made in other areasa problem which becomes exacerbated if costs escalate. These cuts affect those "who were least likely to enjoy benefits from the mega-events (or even to attend them): the urban poor, Aboriginals and people in country districts a long way from the city" (Whitson 2004:1227-1228). In this regard, there are significant social costs stemming from the diversion of public funding associated with closure of facilities and the failure to provide services (Whitson and Horne 2006; Whitson 2004). The social impacts attached to mega-events are important and the international literature highlights that this is a problem not restricted to the developing world.

In this regard, Andranovich et al. (2001) argue that urban regeneration projects in Atlanta (host of the 1996 Olympics) did not improve conditions for urban residents and that hosting a mega-event does not necessarily provide opportunities for these goals to be met. Indeed, "providing festivals when people need bread is a dubious use of public resources" (Andranovich et al. 2001:127). This argument is extended in the context of Australia by Lenskyj (2002) who considers the social impacts of the Sydney 2000 Olympics. She argues that the Olympics aggravated the existing housing gap. Moreover, she contends that homelessness and housing social problems increased in the run up to the Olympics. Furthermore, job creation was mainly temporary (Lenskyj 2002). Lenskyj (2002:227-228) contends that "in the streets, low-income neighbourhoods, homeless refuges, and Indigenous communities - there was indisputable evidence that the staging of the Olympics served the interest of global capitalism first and foremost while exacerbating existing social problems". This is a point which developing countries should be attuned to.

Clearly, a model is needed which takes into account the effects of residential displacement and rising property values in neighbourhoods adjacent to stadium precincts (Hiller 1998). It has been estimated that the 1988 Seoul Olympics resulted in the eviction of 700,000 people; 300,000 have been displaced for the upcoming Beijing Olympics. Furthermore, evictions are expected in London before that city hosts its Olympics in 2012 (Horne and Manzenreiter 2006). Problems in this regard were also experienced in Barcelona and Sydney reminding one that "increased social polarisation also remains one of the major legacies of mega-events" (Horne and Manzenreiter 2006:12). It seems that there are "few social benefits for those unable (or dis-inclined [sic]) to present themselves as consumers" (Whitson and Horne 2006:86).

Having broadly considered the impacts of mega-events, through a digest of aspects of the international literature, the argument now turns more directly to an examination of the impacts of major events in the developing world, with an emphasis on their implications for poverty reduction. 


\section{A Mechanism for Poverty Reduction in the Periphery?: Insights form the International Literature}

The developing world, in particular Asia and South America, has played host to a number of mega-events. In addition, there are many upcoming mega-events scheduled to take place in developing or peripheral countries. These include: the 2010 FIFA World Cup, hosted by South Africa; the 2010 Commonwealth Games, hosted by India; the 2008 Beijing Olympics in China and the 2012 UEFA Football Championship in Poland and Ukraine (Cornelissen 2007; Humphreys and Prokopowicz 2007). Yet, Humphreys and Prokopowicz (2007:496) suggest that "mega-events may not be effective regional economic development vehicles in transition economies". In this context, it is increasingly important to assess the impacts of mega-events in the periphery with specific reference to poverty reduction. Again, the literature is hampered by a lack of sufficient longitudinal studies. Nevertheless, the existing literature does not offer much evidence that hosting megaevents has a direct effect on poverty reduction.

Research into mega-events and developing nations has been centred on questions of development, place promotion, signalling, identity building and human rights and political liberalisation (Black and Bezanson 2004; Black and van der Westhuizen 2004). While attention in this piece is focused mainly on developmental impacts related to poverty reduction, it is pertinent to note that, as evidenced from the case of Malaysia and its hosting of the 16th Commonwealth Games, mega-events may prompt nefarious outcomes in the form of strengthening authoritarian regimes (van der Westhuizen 2004). In addition, another point worthy of consideration centres around the notion that in seeking to project positive images of themselves, developing nations often have to work against stereotypical media images. Developing countries are generally projected in a negative light and media outlets tend to perpetuate rather than challenge these images. The 1996 Cricket World Cup in India, Pakistan and Sri Lanka serves as an example of this (Dimeo and Kay 2004). This is particularly relevant to the South African context, where the international and local media have already cast doubt internationally over the ability of South Africa to successfully host the World Cup and have publicly touted potential alternative host countries. Finally, one should not neglect the intangible benefits in terms of image enhancement, nation and identity building and publicity and the indirect impacts these might have on poverty reduction (Matheson and Baade 2004). Yet, Whitson and Horne (2006) warn that history suggests that the long-term place-promotion of peripheral cities has transient impacts.

For developing countries, the primary motivating reason for hosting a mega-event is the unsubstantiated "promise of an economic windfall" (Matheson and Baade 2004:1085). However, "claims that sports mega-events provide a substantial boost to the economy of the host city, region, and country have been strongly criticised" (Matheson and Baade 2004:1089). Reviewing the consequences of mega-events in the periphery, Matheson and Baade (2004) point out that spending on infrastructure is considerably higher in developing countries. Yet evidence suggests that the construction of stadiums in Japan, associated with the 2002 co-hosted World Cup with Korea, may rather have been "steroids, bloating rather than strengthening the economy" (McCormack, cited in Horne 2004:1242). The event failed to live up to the organisers' expectations (Cornelissen and Swart 2006). In addition, similarly to 
the aftereffects of the Nagano Winter Olympics in 1998, stadium maintenance costs continue to be borne by tax payers. After the conclusion of the World Cup, facilities created in Japan were used by professional, commercial sport and concerts (rather than for facilities for the public), and social goals "that might follow from highquality public infrastructure for sport and recreation, are still far from being accomplished" (Whitson and Horne 2006:75).

The perception exists that some 'trickle down' effects occur and that benefits may accrue from spending on infrastructure that is not sports-related. For example, in the case of Beijing, sport facilities will account for a mere fraction of the $\$ 22$ billion allocated to improvements in infrastructure (Matheson and Baade 2004). Nevertheless, in parallel to the situation in the developed world, Matheson and Baade (2004:1092) suggest that the:

"opportunity cost of capital may also be particularly high in developing nations.

From an economic point of view, the cost of building a new stadium is not best described by the amount of money needed to build the facility but rather the value to society from the same amount of capital spent on the next best public project".

Cornelissen (2007:5) concurs, observing that mega-events "may involve infrastructural and other developments, the legacies of which may be to the disadvantage, rather than the advantage of the broader populace". There is widespread agreement that for the urban poor, the value or legacies of stadium and other facilities remain debatable (Whitson and Horne 2006). In this regard, there is not an undisputed link between infrastructure and facilities development and poverty reduction.

Furthermore, it is pertinent to address whether mega-events contribute to poverty reduction in terms of employment. It is important to assess whether local residents will benefit from earnings associated with the mega-event and whether these earnings will remain after the conclusion of the event. The literature indicates that claims of job creation associated with mega-events need to be treated cautiously (Horne and Manzenreiter 2006; Matheson and Baade 2004).

Tourism benefits are also provisional in the developing world context. Korea did not receive the expected boost in tourism post-Olympics or post-World Cup (Horne and Manzenreiter 2006; Whitson 2004). Indeed, in 2002, the year of the World Cup, South Korea received approximately the same number of visitors as they had in 2001; Japan cited an increase of 30,000 visitors (Horne and Manzenreiter 2006). Furthermore, as Horne and Manzenreiter (2004) point out in their study of the Japan/Korea World Cup, a gap between actual and forecasted impacts is to be expected. Thus, claims resulting from poverty reduction linked to tourism strategies need to be carefully considered in the context of the developing world.

Hence, the literature on development and mega-events suggests that there is little to corroborate (in terms of political liberalisation, place-promotion, infrastructure and facilities development, job creation and tourism impacts) the notion that poverty will be addressed in a significant way.

\section{Insight into 2010 FIFA World Cup and Development Prospects to South Africa}

If the international literature is heavily cautious regarding the developmental benefits of mega-events and their capability to alleviate poverty in the developing world, it is 
apposite to address the development prospects for South Africa associated with its hosting of the 2010 FIFA World Cup.

Mega-events have become prominent in the South African context due to the perceived benefits of nation building, international profiling and economic and developmental gains (Cornelissen and Swart 2006; Cornelissen 2004b, 2005, 2007). Rhetoric by the Gauteng Premier, Mbhazima Shilowa (cited in Gonzalez 2007:2), supports the notion that the South African "vision remains that of halving poverty and unemployment by 2014, and the 2010 World Cup provides an opportunity to fast-track development towards attainment of this vision". Certainly, the notion of a developmental agenda has become a key feature of South Africa's mega-event strategy (Cornelissen 2004a, 2004b, 2005; Cornelissen and Swart 2006; Swart and Bob 2004). Hiller (1998, 2000) highlights the kind of development agendas associated with bidding for mega-events in the South African context. These include a commitment to construct facilities in areas that are disadvantaged; the notion that facilities development stimulates further initiatives; the enhancement of disadvantaged communities' sport programmes; job creation; provision of affordable housing; small business support, provision of an integrated transport system and community consultation. Poverty reduction strategies are therefore centred around black economic empowerment initiatives, job creation, transportation integration and township regeneration. Such agendas remain prominent in connection with the FIFA World Cup. Despite this, there is a paucity of research that evaluates the likelihood of South Africa to achieve social and economic gains from the hosting of megaevents (Cornelissen 2004b).

While 2010 does offer South Africa the opportunity to deliver on the social and political promises associated with its mega-event strategy, it will be a vast challenge to balance investment with the socio-economic needs of the populace (Cornelissen and Swart 2006). Furthermore, as Swart and Bob (2004:1322) indicate (in the context of the failed Cape Town Olympic bid) it "is doubtful whether the global intervention promise of alleviating the poverty trap via the hosting of mega-events in South Africa will be realised". Such an insight is particularly relevant to the hosting of the FIFA World Cup. In addition, as Cornelissen (2004b, 2005) suggests, the opportunity costs associated with hosting mega-events may be too high for South Africa and that questions must be asked concerning whether the benefits will be greater than the costs.

While proponents of mega-events position them as "pro-growth strategies for long-term economic development and job creation" (Hiller 2000:439), it is the link to pro-poor agendas that becomes particularly relevant in the South African context. Crucial questions remain regarding the distribution of benefits and the balance between growth and redistribution imperatives (Horne and Manzenreiter 2006). In South Africa, the tension between pro-growth and pro-poor agendas is particularly acute, given the twin priorities of international growth and redistribution. In accordance with this economic balancing act, pro-growth mega-events are often linked to notions of the public good. Yet, despite assertions in the popular domain to the contrary, development linked to the World Cup is not pro-poor (Tilley 2006). The World Cup can "only be developmental to the extent that there...[is] a deliberate will to make them so. Embracing principals and putting them in operation are two different things - constantly endangered by finances, time constraints and politics" 
(Hiller 2000:454). Given the international uncertainty that surrounds the economic benefits of hosting mega-events, it is problematic to assume that income will materialise to advance the pro-poor agendas of service delivery and social redress.

It is particularly questionable if mega-events are able to assist in addressing poverty by assisting with housing provision in South Africa - an insight which should inform 2010 planning. Firstly, the type of housing which needs to be provided would likely exceed entry level requirements and the associated costs would serve to exclude the poor (Hiller 1998). In the context of the assertions of the failed Cape Town Olympic bid, it is suggested that:

"the enormity of the housing problem in relation to the type of housing that would be built suggested that housing expectations would not be realized at all. The quantity of housing needed for the Olympics was nowhere near what was needed in the city and in that sense created unrealistic expectations" (Hiller 1998:54).

In addition, it is important to bear in mind that stadiums or training facilities situated in disadvantaged communities could alter (as the international experience suggests) the value of property in the adjacent areas, thus changing the character of the area. The unintended consequences could include a transformation of the social class and an escalation of rents beyond the affordability of renters. Instead of benefiting, the urban poor might be negatively affected by the upward movement of property markets (Whitson and Horne 2006; Hiller 1998, 2000). Thus, while urban regeneration associated with stadium precincts may stimulate property prices, higher rents and gentrification are likely to displace the poor out of adjacent residential areas (Tilley 2006). Perhaps a significant warning to those espousing developmental gains, projects initiated in relation to the failed Cape Town bid have failed to be incorporated into, or contribute to further development initiatives or other megaevent strategies (Cornelissen and Swart 2006).

The benefits associated with infrastructural provision also require careful examination. The "debate on the infrastructural and economic legacies, the distribution of these, and access to opportunities, has also started to intensify" (Cornelissen and Swart 2006:118). Closely linked with Matheson and Baade's (2004) three categorisations of complaints, Tilley (2006) warns that spending on infrastructure could displace public funds and perhaps delay other projects in the public interest. Moreover, Matheson (2002:2) reports that "independent work on the economic impact of mega-sporting events has routinely found that the effect of these events on host communities is either insignificant or an order of magnitude below the figures espoused by the sports' promoters". Consequently, the literature points to the fact that infrastructure provision does not benefit local residents and are often not significantly used postevent. Furthermore, the expected "under-utilisation of the facilities built will mean that not all localities will obtain the benefits promised" (Horne and Manzenreiter 2006:14). A longer term view of the stadiums, facilities and infrastructure must be considered so as to mitigate against potential negative consequences (Cornelissen 2004a). As such, vigorous debate currently exists around the benefits and legacies of major infrastructural projects, notably the Gautrain and King Shaka International Airport, and their potential to reduce poverty. It is to be expected that the long-term job creation effects associated with these projects will not be high and questions have been asked of the ability of the Gautrain to benefit the urban poor (McKenzie 2007). 
It is likely that improvements in transportation, infrastructure, service provision and the quality of the urban fabric will be highly centralised and their benefit for marginal urban areas, rural areas and non-host cities limited.

Literature on the impacts of mega-events on non-host cities and rural areas is minimal. Deccio and Baloglu (2002) offer some treatment of the subject while Kim and Petrick (2005) and Jones' (2001) commentary is more oblique. Arguably, the potential impact of the World Cup is not confined to the host country. Indeed, impacts can include economic, political, historical factors and the odds of a country winning the tournament. In fact, based on a combination of these factors, it is evident that the 1998 French World Cup had the greatest impact in Brazil (Anonymous 1998)! Notwithstanding this, Deccio and Baloglu's (2002) study reveals that non-host communities do not anticipate that mega-events will have an impact on their local community; although, it is thought that some opportunities will arise. Bearing this in mind, it is apposite to briefly assess the potential impact of the 2010 World Cup on the areas beyond host, South African cities.

The rhetoric swirling around 2010 tends to suggest that benefits could be widespread. Fan parks and clubs, for example, are planned for non-host South African cities and unofficial parks are planned in other parts of Africa (Mbanjwa, 2007, interview; City Press 2007; Phillips 2007). It has also been suggested that neighbouring countries such as Swaziland and Mozambique will form the bases and practice locations for foreign teams; thus, dispersing economic and supporters' benefits (City Press 2007).

In addition, tourism benefits beyond host city boundaries are often cited. Indeed, as Lee and Taylor (2005:595) observe, "mega sport events such as the FIFA World Cup...draw significant numbers of domestic and international tourists". Despite Horne and Manzenreiter's (2006) contention above that South Korea received a similar number of visitors in the World Cup year as in the previous year, Lee and Taylor (2005) calculate that during the World Cup in South Korea, 57.7\% of foreign tourist arrivals were either direct or indirect World Cup tourists. The expenditure, per capita, of these tourists was approximated at $\$ 2,242$ which represented a figure 1.8 times greater than regular tourists. In total, foreign tourist expenditure was estimated at $\$ 522$ million. Based on these figures, "it was calculated that the World Cup generated an economic impact of US\$1.35 billion of output (sales), US\$307 million of income and US\$713 million of value added for South Korea" (Lee and Taylor 2005:595). While the general mega-event hope is to attract these visitors to other areas of the country, it is questionable whether sports tourists will sample the larger tourism product (Higham 1999).

Thus, one must be cautious of overstating the benefits to be obtained from tourism. It is not only South Africa who should take heed of this advice. Neighbouring countries such as Mozambique are also hoping to profit from increased tourism stemming from 2010 (EARTHtimes.org 2007). Tourism impacts are as yet untested and claims should not be accepted at face value. While 2010 will provide key tourists, Doreen Atkinson (2007, interview) suggests that tourism planners have not properly examined the potential of tourism corridors between host cities. In addition, any thinking about tourism and 2010 in South Africa thus far occurring tends to be compartmentalised into provinces - instead of a more holistic cross-provincial strategy (Doreen Atkinson, 2007, interview). Hence, there is little 
evidence to support the notion that the impacts of 2010 will flow out of the host cities and contribute to poverty amelioration on a broader scale.

The general perception that mega-events will benefit impoverished communities is based on the assumption of a 'trickle-down' effect. This may not be accurate as growth might create difficulties for the poor and job creation is temporary and low paying (Hiller 2000). It is expected that during the construction phase and the 2010 World Cup event itself, employment will rise and attract migrants from rural areas. However, due to the temporary nature of the employment created, post-2010 urban unemployment is consequently expected to swell. Moreover, food and transportation prices are anticipated to permanently rise in South Africa (Tilley 2006). These results would hinder rather than enable the daily strategies of marginalised communities. Hence, mega-events can become symbols of "economic growth through anticipated inward investment and job creation-even if it...[is] unproven and perhaps wishful thinking" (Hiller 2000:454).

Usefully, Tilley (2006) offers some constructive suggestions regarding how to avoid these pitfalls in the South African context. Importantly, a sense of realism must prevail and there should be a commitment to ensuring that new developments and stadiums are designed to incorporate a variety of activities. Furthermore, infrastructure and tourism developments should not merely be urban-based but focus attention on other areas as well. Incentive grants could be provided to communities to establish curio stalls and refreshment stands which might attract tourists and, in such a manner, contribute to poverty reduction. As she suggests, such long-term, integrated development "could help make the World Cup a genuine economic boon to SA, rather than a hard lesson in mistaken enthusiasm" (Tilley 2006:3).

\section{Conclusion: Legacy Matters!}

A review of the international literature, including a contextual location as it applies to South Africa's preparation for the 2010 World Cup, has left much concern about the benefits that could accrue from a 'fast-tracked' programme of urban development, with potential spin-offs for the country as a whole. In addition, the cautionary reminders that were posed some time back, which had serious resonance and needed to be taken seriously in order to advance principles of pro-active planning (hopefully) eventuating in benefits that would accrue to all South Africans, have not materialised.

Having said this, it is overly tempting to see the legacy that 2010 needs to leave behind in terms articulated exclusively in a 'pro-poor' language. In other words, there is a body of thought that posits that for 2010 to have been deemed successful, the primary beneficiaries must be the poor, marginalised and impoverished. The argument is that in the run-up to 2010 and, indeed, after the event, the value of the spectacle must be measured, inter alia, by the number of jobs created (particularly in the 'second economy'), the extent to which services to the poor have been accelerated, how the public transport system has been enhanced to cut - and make more safe and reliable - commuting time between place of residence and work, the net contribution to the GDP to allow redistribution and social grant programmes to gain momentum, and whether other reconstruction, development and 'welfare-based' Accelerated and Shared Growth Initiative for South Africa (ASGISA) objectives can 型 Springer 
be fulfilled. Indeed, a recent Human Sciences Research Council (HSRC) attitudinal survey measuring public perceptions on 2010 - to be conducted annually-revealed that one in three South Africans expect to benefit personally from a job creation opportunity through 2010 - presumably through some sort of large public works programme or the other. There is also a growing body of thought that argues that 2010 can make significant in-roads in changing the anomalous form and structure of South African cities, brought on by decades of apartheid spatial planning.

This paper has maintained and argued that issues of growth and equity as mutually reinforcing concepts are crucial if 2010 is to meet with the kinds of successes hoped for. It has also argued that the success of the event will be measured not only in terms of how South African cities are made more competitively globally, but in terms of how an undertaking to the poor and indigent can be fulfilled.

Given this, and despite somewhat pessimistic conclusions about the event's development prospects, what has been of concern most recently is the framing of this debate in mutually exclusive terms. To use two examples, representing in effect polarised ideological positions, either jobs are created and the plight of the poor improved by doing so through 2010, or focus is given to the opportunities created by the event to attract foreign direct investment that will help grow the economy to $6 \%$ per annum. It is not possible, so the argument goes, do both. This is where South Africa may getting it wrong. These goals (and a whole subset beneath them) are not contradictory, and had a debate started with much urgency around these issues soon after the event was awarded to the country, the World Cup could have been conceived as one truly beneficial to all South Africans.

What was required was a consensus-driven understanding by all stakeholders and constituencies. If these stakeholders worked together, pooled resources, aligned visions, collectively charted processes, and conjointly identified targets, the end result could have truly benefited the country as a whole, and not just specific sectors. While competing discourses on development were important as the planning and the roll-out of large programmes required to make 2010 a success began 2 years ago, this should have not come at the expense of a collective vision, one based not just on consensus (consensus, after all is often about compromise), but one based on a recognition of what was truly best for the country given its enormous challenges.

This potential meeting of minds would have agreed that not all of South Africa's urban 'ills' would be solved by 2010 nor, conversely, would the country immediately join a global hierarchy - an elite list as it were-of competitive national economies. It would also have agreed that 2010 would create jobs, but not solve unemployment problems; that it would improve the public transport system, but not solve the public transport problem; that it would help accelerate service delivery in some of the urban townships, but only marginally; that it would position the country more competitively, but not before getting more of the basics right-like crime and industrial policy; that South Africa would have world class facilities to attract mega-events in future, but for the large part these are likely to be underutilised in future; that there was likely to be a positive net contribution to the GDP, but that 2010 itself was unlikely to deliver a $6 \%$ growth rate.

This is not necessarily a new argument but rather simply a positing that South Africa's 2010 legacy needed to have been broadly defined at the outset. This has not happened! If $74 \%$ of South Africans, as the previously mentioned HSRC survey 
revealed, are optimistic about a combination of job prospects, economic growth and international standing that may result from 2010, surely policy makers, practitioners, civil society and scholars had an obligation to make sure that in the many 2010 meetings, round-tables and forums participated in over the past few years, a consensus was negotiated about anticipated benefits and prospective costs. It has become increasingly evident that there is a current disjuncture between what people on the ground are and have been saying and feeling about 2010 (the survey again reveals illuminating insights), and the way this is and has been articulated by their leaders and representatives. One had every reason to believe that a resident of Athlone, plying his or her informally based trade in the centre of Cape Town, found it quite exciting that 2010 would result in a flurry of foreign tourists. Similarly, one felt confident that the boardroom executive in Sandton overlooking the sprawling township of Alexandra recognised the (longer-term) benefits that could accrue to the national economy from an upgrade of the township ahead of 2010.

Perhaps this is overstating the cracks and not sufficiently highlighting reasonable consensus that may have already been reached on theses issues. But if recent debates, and much unpleasantness, around the Gautrain, Green Point Stadium, the N2 Gateway project and La Mercy airport are anything to go by on, consensus was only partly and ephemerally reached. The words 'trade-off', 'trickle-down' and 'best practice' are not ones which inspire fondness. Additionally, in a crudely defined 'rich'/'poor' continuum, especially as development agendas took root ahead of 2010, necessary checks and balances were needed to avoid outcomes that create tension and unnecessary conflict. But somewhere in between all of this, more critically, a national consensus needed to have been arrived at, driven by South Africa's leaders, on what kind of legacy 2010 was realistically and practically likely to leave behind. Legacy outcomes, after all, are not zero-sum games.

In sum, though, the evidence from the international literature unequivocally suggests that more widespread development benefits are not a direct consequence of spending associated with mega-events. Inequality may even be exacerbated by the hosting of the World Cup. Past experience suggests that there is no proof that the hosting of mega-events will result in meaningful job creation, a significant contribution to the GDP or infrastructural, service and facilities provision that is appropriate beyond the lifespan of the event. South Africa needed to be acutely aware of this notion if it was to balance the pro-growth and pro-poor imperatives of its mandate. Despite assertions on the behalf of government that 2010 will 'deliver', widespread and sustained poverty alleviation-as the argument above has articulated - is unlikely to be a significant outcome of the 2010 FIFA World Cup. Nor is urban development beyond the immediate requirements of the event itself.

Notwithstanding this, it is still argued - even at this late stage - that the definition of legacy be expanded and opened up to public and popular debate, and informed by rigorous scholarly research.

Open Access This article is distributed under the terms of the Creative Commons Attribution Noncommercial License which permits any noncommercial use, distribution, and reproduction in any medium, provided the original author(s) and source are credited. 


\section{References}

Anonymous (1998). The world cup impact ranking. Crossborder Monitor, 17(6), 24.

Andranovich, G., Burbank, M. J., \& Heying, C. H. (2001). Olympic cities: lessons learned from megaevent politics. Journal of Urban Affairs, 23(2), 113-131.

Baade, R. A., \& Matheson, V. A. (2004). The quest for the cup: assessing the economic impact of the World Cup. Regional Studies, 38(4), 343-354.

Black, D. R., \& Bezanson, S. (2004). The olympic games, human rights and democratisation: lessons from Seoul and implications for Beijing. Third World Quarterly, 25(7), 1245-1261.

Black, D. R., \& van der Westhuizen, J. (2004). The allure of global games for 'semi-peripheral' polities and spaces: a research agenda. Third World Quarterly, 25(7), 1195-1214.

Burbank, M. J., Andranovich, G., \& Heying, C. H. (2002). Mega-events, urban development and public policy. The Review of Policy Research, 19(3), 179-202.

City Press. (2007). Province mobilises fans ahead of 2010 World Cup. City Press, 24 June, 16.

Cornelissen, S. (2007). China and the 2008 Beijing olympics: the dynamics and implications of sport mega-events in the semi-periphery. The China Monitor, 18, 4-5.

Cornelissen, S. (2005). The global tourism system: governance, development and lessons from South Africa. Aldershot: Ashgate.

Cornelissen, S. (2004a). 'It's Africa's turn' the narratives and legitimations surrounding the Moroccan and South African bids for the 2006 and 2010 FIFA finals. Third World Quarterly, 25(7), 1293-1309.

Cornelissen, S. (2004b). Sport mega-events in Africa: processes, impacts, prospects. Tourism and Hospitality Planning and Development, 1(1), 39-55.

Cornelissen, S., \& Swart, K. (2006). The 2010 Football World Cup as a political construct: the challenge of making good on an African promise. In J. Horne, \& W. Manzenreiter (Eds.), Sports mega-events: social scientific analyses of a global phenomenon (pp. 108-123). Blackwell/The Sociological Review: Malden, USA.

Deccio, C., \& Baloglu, S. (2002). Nonhost community resident reactions to the 2002 winter olympics: the spillover impacts. Journal of Travel Research, 41, 46-56.

Dimeo, P., \& Kay, J. (2004). Major sport events, image projection and the problems of 'semi-periphery': a case study of the 1996 South Asia Cricket World Cup. Third World Quarterly, 25(7), 1263-1276.

EARTHtimes.org. (2007). Mozambique invests in tourist sector in run-up to World Cup 2010. EARTHtimes.org, 14 August. http://www.earthtimes.org/articles/show/93262.html. Cited 16 August 2007.

Emery, P. R. (2001). Bidding to host a major sports event: strategic investment or complete lottery. In C. Gratton, \& I. P. Henry (Eds.), Sport in the city: the role of sport in economic and social regeneration (pp. 90-108). Routledge: London.

Gonzalez, L. L. (2007). Poor can rise on the back of 2010. Star, 27 June, 2.

Gratton, C., Dobson, N., \& Shibli, S. (2001). The role of major sport events in the economic regeneration of cities: lessons for six World or European Championships. In C. Gratton, \& I. P. Henry (Eds.), Sport in the city: the role of sport in economic and social regeneration (pp. 35-45). Routledge: London.

Gratton, C., Dobson, N., \& Shibli, S. (2000). The economic importance of major sports events: a case study of six events. Managing Leisure, 5, 17-28.

Gratton, C., Shibli, S., \& Coleman, R. (2006). The economic impact of major sports events: a review of ten events in the UK. In J. Horne, \& W. Manzenreiter (Eds.), Sports mega-events: social scientific analyses of a global phenomenon (pp. 41-58). Blackwell/The Sociological Review: Malden, USA.

Higham, J. (1999). Commentary — sport as an avenue of tourism development - an analysis of the positive and negative impacts of sport tourism. Current Issues in Tourism, 2(2), 82-90.

Hiller, H. H. (2000). Mega-events, urban boosterism and growth strategies: an analysis of the objectives and legitimations of the Cape Town 2004 Olympic Bid. International Journal of Urban and Regional Research, 24(2), 439-458.

Hiller, H. H. (1998). Assessing the impact of mega-events: a linkage model. Current Issues in Tourism, 1 (1), 47-57.

Horne, J. (2004). The global game of football: the 2002 World Cup and regional development in Japan. Third World Quarterly, 25(7), 1233-1244.

Horne, J., \& Manzenreiter, W. (2004). Accounting for mega-events: forecast and actual impacts of the 2002 Football World Cup Finals on the host countries Japan/Korea. International Review for the Sociology of Sport, 39(2), 187-203. 
Horne, J., \& Manzenreiter, W. (2006). An introduction to the sociology of sports mega-events. In J. Horne, \& W. Manzenreiter (Eds.), Sports mega-events: social scientific analyses of a global phenomenon (pp. 1-24). Blackwell/The Sociological Review: Malden, USA.

Humphreys, B. R., \& Prokopowicz, S. (2007). Assessing the impact of sports mega-events in transition economies: EURO 2012 in Poland and Ukraine. International Journal of Sport Management and Marketing, 2(5/6), 496-509.

Jones, C. (2001). Mega-events and host-region impacts: determining the true worth of the 1999 Rugby World Cup. International Journal of Tourism Research, 3(3), 241-251.

Kim, S. S., \& Petrick, J. F. (2005). Residents' perceptions on impacts of the FIFA 2002 World Cup: the case of Seoul as a host city. Tourism Management, 26, 25-38.

Lee, C., \& Taylor, T. (2005). Critical reflections on the economic impact assessment of a mega-event: the case of 2002 FIFA World Cup. Tourism Management, 26, 595-603.

Lenskyj, H. J. (2002). The best olympics ever? Social impacts of Sydney 2000. Albany: State University of New York Press.

Matheson, V. A. (2002). Upon further review: an examination of sporting event economic impact studies. The Sport Journal, 5(1), 1-4 http://www.thesportjournal.org/2002Journal/Vol5-No1/studies.asp. Cited 20 June 2007.

Matheson, V. A., \& Baade, R. A. (2004). Mega-sporting events in developing nations: playing the way to prosperity? The South African Journal of Economics, 72(5), 1085-1096.

Metropolis (2002). Commission 1: The impact of major events on the development of large cities. Barcelona: World Association of the Major Metropolises, Metropolis.

McKenzie, K. (2007). Public transport in the spotlight. Delivery, 10, 14-18.

Owen, J. G. (2005). Estimating the cost and benefit of hosting Olympic Games: What Can Beijing expect from its 2008 games? The Industrial Geographer, 3(1), 1-18.

Philips, M. (2007). World Cup looks good for Africa, apart from on the pitch. Reuters UK, 21 August. http://uk.reuters.com/articlePrint?articleID=UKL2065790520070821. Cited 21 August 2007.

Pillay, U. (2004). Are globally competitive 'city regions' developing in South Africa?: formulaic aspirations or new imaginations? Urban Forum, 15(4), 340-364.

Pillay, U., Tomlinson, R., \& du Toit, J. (2006). In Democracy and delivery: Urban policy in South Africa. Cape Town: HSRC Press.

Ritchie, J. R. B. (2000). Turning 16 days into 16 years through Olympic legacies. Event Management, 6, $155-165$.

Speake, J. (2007). Sensational cities. Geography, 92(11), 3-12.

Spilling, O. R. (1998). Beyond intermezzo? On the long-term industrial impacts of mega-events-the case of Lillehammer 1994. Festival Management \& Event Tourism, 5, 101-122.

Swart, K., \& Bob, U. (2004). The seductive discourse of development: the Cape Town 2004 Olympic bid. Third World Quarterly, 25(7), 1311-1324.

Tilley, V. (2006). Scary economics of the mega event. Business Day, 8 August. http://www.businessday. co.za/PrintFriendly.aspx?ID=BD4A194528. Cited 20 June 2007.

van der Westhuizen, J. (2004). Marketing Malaysia as a model modern Muslim state: the significance of the 16th Commonwealth Games. Third World Quarterly, 25(7), 1277-1291.

Whitson, D. (2004). Bringing the world to Canada: 'The periphery of the centre'. Third World Quarterly, 25(7), 1215-1232.

Whitson, D., \& Horne, J. (2006). Underestimated costs and overestimated benefits? Comparing the outcomes of sports mega-events in Canada and Japan. In J. Horne, \& W. Manzenreiter (Eds.),Sports mega-events: social scientific analyses of a global phenomenon (pp. 73-89). Blackwell/The Sociological Review: Malden, USA.

\section{About the Authors}

Udesh Pillay is an Executive Director at the Human Sciences Research Council, Pretoria, South Africa.

Orli Bass is a Post-Doctoral Fellow at the Human Sciences Research Council, Durban, South Africa. 